\title{
Análise econômica da produtividade de grãos de milho consorciado com forrageiras dos gêneros Brachiaria e Panicum em sistema plantio direto
}

\author{
Cássia Maria de Paula Garcia', Marcelo Andreotti², Maria Aparecida Anselmo Tarsitano ${ }^{3}$, \\ Marcelo Carvalho Minhoto Teixeira Filho ${ }^{4}$, Ana Elisa da Silva Lima ${ }^{5}$. Salatiér Buzetti ${ }^{6}$
}

\begin{abstract}
RESUMO
O sistema de integração lavoura-pecuária (ILP) é uma alternativa de recuperação e renovação de pastagens degradadas, contudo, é importante mostrar sua viabilidade econômica. O objetivo deste trabalho foi analisar a produtividade de grãos e os resultados econômicos de modalidades do cultivo de milho com forrageiras dos gêneros Panicum e Brachiaria, na ILP, em sistema plantio direto. O experimento foi conduzido no ano agrícola de 2009/2010, em SelvíriaMS, em Latossolo Vermelho distroférrico. O delineamento experimental utilizado foi o de blocos casualizados, com quatro repetições, sendo os tratamentos constituídos por oito modalidades de cultivo do milho consorciado, simultaneamente e por ocasião da adubação nitrogenada de cobertura com as forrageiras Brachiaria brizantha cv. MG-5, Brachiaria ruziziensis, Panicum maximum cv. Tanzânia e cv. Mombaça. A análise dos custos operacionais foi baseada nos preços de insumos e operações e a receita bruta no preço médio de venda do milho no Estado de São Paulo. Os sistemas de cultivo não reduziram a produtividade de grãos em relação ao milho cultivado sem consórcio, e o consórcio mais recomendado é o milho cultivado com B. ruziziensis, principalmente em semeadura simultânea, pois além de ter sido um dos mais produtivos, o preço dessa semente é o mais acessível, vindo alcançar maior Índice de Lucratividade que os demais tratamentos. Em geral, os cultivos simultâneos foram os mais produtivos, vindo a apresentar maior Receita Bruta, Custo Operacional Total (devido à aplicação do herbicida Sanson), menor Lucro Operacional (com exceção do MBS) e maior Índice de Lucratividade.
\end{abstract}

Palavras-chave: Zea mays L., integração lavoura-pecuária, custo operacional total, índice de lucratividade.

\section{ABSTRACT}

\section{Economic analysis of grain yield of maize intercropped with forage plants of the genera Brachiaria and Panicum in no-tillage system}

The integrated crop-livestock (ILP) is an alternative recovery and renewal of degraded pastures; however, it is important to show its economic viability. The objective of this research was to analyse the yields and economic outcomes of modalities of growing corn with fodder of the genera Brachiaria and Panicum in the ILP under no-tillage.

Recebido para publicação em 08/07/2011 e aprovado em 03/02/2012

${ }^{1}$ Zootecnista, MSc. em Agronomia. Universidade do Estado de São Paulo, Campus de Ilha Solteira, Passeio Jaú, 103, 15385-000, Zona Sul, Ilha Solteira, São Paulo, Brasil. cassiampg@yahoo.com.br *Autora para correspondencia.

${ }^{2}$ Engenheiro-Agrônomo, Doutor. Professor Assistente do Departamento de Fitossanidade, Engenharia Rural e Solos, Universidade do Estado de São Paulo, Campus de Ilha Solteira, Passeio Jaú, 103, 15385-000, Zona Sul, Ilha Solteira, São Paulo, Brasil. dreotti@agr.feis.unesp.br

${ }^{3}$ Engenheira-Agrônoma, Doutora. Departamento de Fitotecnia, Tecnologia de Alimentos e Sócio Economia, Universidade do Estado de São Paulo, Campus de Ilha Solteira, Passeio Jaú, 103, 15385-000, Zona Sul, Ilha Solteira, São Paulo, Brasil. maat@agr.feis.unesp.br

${ }^{4}$ Engenheiro-Agrônomo, Doutor. Departamento da Faculdade de Engenharia, Universidade do Estado de São Paulo, Campus de Ilha Solteira, Passeio Jaú, 103, 15385-000, Zona Sul, Ilha Solteira, São Paulo, Brasil. mcmtf@yahoo.com.br

5Engenheira-Agrônoma, Doutoranda do curso de Agronomia. Universidade do Estado de São Paulo., Campus de Ilha Solteira, Passeio Jaú, 103, 15385-000, Zona Sul, Ilha Solteira, São Paulo, Brasil. anael_lima@hotmail.com

${ }^{6}$ Engenheiro-Agrônomo, Doutor. Departamento de Fitossanidade, Engenharia Rural e Solos, Universidade do Estado de São Paulo, Campus de Ilha Solteira, Passeio Jaú, 103, 15385-000, Zona Sul, Ilha Solteira, São Paulo, Brasil. sbuzetti@agr.feis.unesp.br 
The experiment was conducted in the agricultural year 2009/2010 in Selvíria - MS, Brazil, in a Distroferric Red Latosol (Oxisol). The experimental design was a randomized complete block with four repetitions and the treatments consisted of eight methods of cultivation of maize intercropped with Panicum maximum Jacq cv. Tanzania, Panicum maximum jacq cv. Mombaça, Brachiaria brizantha (Hochst.) Stapf cv. MG-5, or Brachiaria ruziziensis Germain \& Evrard, sown simultaneously or at side dressing nitrogen fertilization, besides single grown corn. The operating cost analysis was based on prices of inputs and operations, and gross revenue in the average selling price of corn in the State of São Paulo, Brazil. The cropping systems didn't reduce the grain yield for maize comparatively to single grown, and the consotium more recommended is corn with B. ruziziensis, especially in simultaneously sowing, because besides being one of the most productive, the price of this seed is the most affordable, obtaining larger Profitability Index than the other treatments. In general, the simultaneous crops were the most productive, having a higher Gross Income, Total Operating Cost (due to herbicide application Sanson), lower Operating Profit (excluding MBS) and higher Profitability Index.

Key words: Zea mays L., crop-livestock integration, total operational cost, profitability index.

\section{INTRODUÇÃO}

A Integração lavoura-pecuária (ILP) tem se tornado uma opção vantajosa, beneficiando duas atividades de importância econômica. A criação de animais para produção de carne e/ou leite e o cultivo de lavouras a fim de proporcionar ganhos mútuos ao produtor, principalmente nas regiões de cerrado, bem como a maioria das evidências, sugere que esse sistema possui melhores aspectos ambientais do que modernos sistemas de monocultura dependentes da alta utilização externa de insumos, como fertilizantes e inseticidas (Allen et al., 2007).

Devido aos grandes investimentos para a formação, recuperação, reforma, adubação e irrigação de pastagens, têm-se buscado técnicas visando à diminuição desses custos, tendo a ILP sob sistema plantio direto (SPD) em diversas regiões do mundo se tornado opção vantajosa, beneficiando a produção de grãos e a pecuária, além de proporcionar resultados socioeconômicos e ambientais positivos (Kluthcouski et al., 2000; Landers, 2007; Tracy $\&$ Zhang, 2008). Atualmente, em áreas de lavoura com solos corrigidos é comum o uso do sistema consorciado de culturas graníferas com forrageiras tropicais, principalmente as dos gêneros Brachiaria e Panicum.

O consórcio é estabelecido anualmente, podendo ser implantado simultaneamente à semeadura da cultura anual ou cerca de 10 a 20 dias após a sua emergência (Kluthcouski et al., 2000), e o conhecimento do comportamento das espécies na competição por fatores de produção evita que essa inviabilize o cultivo consorciado (Kluthcouski \& Aidar 2003). Tal sistema tem sido objeto de estudo de vários pesquisadores (Kluthcouski et al., 2000; Kluthcouski \& Aidar 2003; Portela 2003; Jakelaitis et al., 2005; Alvarenga et al., 2006; Jakelaitis et al., 2006, Borghi \& Crusciol, 2007), os quais relataram que, na mai- oria dos estudos, a presença da forrageira não afetou a produtividade de grãos de milho.

Sendo o milho o cereal mais produzido no Brasil, cultivado em cerca de 13,1 milhões de hectares, com produção aproximada de 54,5 milhões de toneladas de grãos e produtividade média de $4.158 \mathrm{~kg}$ por hectare, na safra 20010/ 2011 (CONAB, 2011) torna-se fundamental em sistemas complexos, como a ILP, o conhecimento dos custos de produção para auxiliar na tomada de decisão quanto a formas de manejo que, além de promoverem aumento da produtividade, resultem em redução de custos e minimizem riscos ambientais.

De acordo com Trecenti et al. (2008), a ILP tem condições de viabilizar uma propriedade, já que o consórcio de milho com capim-marandu proporcionou incremento de $27 \%$ na rentabilidade da atividade quando comparada com a cultura do milho sem consorciação. Muniz et al. (2007) e revisões de Macedo (2009) também demonstraram que a ILP é uma atividade economicamente lucrativa, sendo uma opção viável para investidores do agronegócio na região dos Cerrados.

Outros resultados comprovam que o sistema de ILP pode gerar elevadas produtividades, seja do componente animal ou do vegetal. Assim, a alta produtividade e a redução de custos de produção são fatores-chave para que sistemas de ILP sejam economicamente viáveis (Fontaneli et al., 2000) e exibam menor risco de insucesso econômico ao longo do tempo (Ambrosi et al., 2001).

Em trabalhos de Costa \& Macedo (2001), Cobucci et al. (2007), Muniz (2007) e Martha Júnior et al. (2008), foram demonstradas vantagens econômicas dos sistemas de ILP sobre os tradicionais contínuos, tendo a maioria apresentado vantagens nas taxas de investimento e no valor presente líquido. 
Uma medida importante de rentabilidade da atividade agropecuária é o índice de lucratividade, uma vez que mostra a taxa disponível de receita da atividade após o pagamento de todos os custos operacionais, inclusive as depreciações. Esse é um indicador que mostra a relação entre o lucro operacional e a receita bruta em percentagem (Tsunechiro et al., 2006).

Diante do exposto, o objetivo deste trabalho foi analisar a produtividade de grãos e os resultados econômicos de modalidades do cultivo de milho com forrageiras dos gêneros Panicum e Brachiaria, na ILP, em sistema plantio direto.

\section{MATERIAL E MÉTODOS}

O experimento foi conduzido na safra 2009/2010, em área experimental pertencente à Faculdade de Engenharia - UNESP, localizada no município de Selvíria - MS, com altitude de $335 \mathrm{~m}$. O solo é classificado como Latossolo Vermelho distrófico, textura argilosa, o qual foi originalmente ocupado por vegetação de cerrado e está sendo cultivado por culturas anuais há mais de 25 anos, sendo em SPD há oito anos (cultura anterior milho). A temperatura média anual é de $23,5^{\circ} \mathrm{C}$, a precipitação pluvial média anual é de $1.370 \mathrm{~mm}$, com umidade relativa do ar média anual entre 70 e $80 \%$. A área experimental foi irrigada por aspersão (pivô central), conforme as necessidades das culturas. Durante a condução do experimento foram monitoradas: a precipitação pluvial (mm), umidade relativa do ar $(\%)$ e as temperaturas $\left({ }^{\circ} \mathrm{C}\right)$ máxima, média e mínima (Figura 1).
Os atributos químicos iniciais na camada de 0 a 0,20 m do solo da área experimental foram, respectivamente, 20 mg dm${ }^{-3}$ de P; $22 \mathrm{~g} \mathrm{dm}^{-3}$ de $\mathrm{MO}$, $\mathrm{pH}$ em $\mathrm{CaCl}_{2}$ de 4,8; teores de $\mathrm{K}, \mathrm{Ca}, \mathrm{Mg}, \mathrm{H}+\mathrm{Al}$ e $\mathrm{Al}$, respectivamente de 3,6; 20; 10; 38; e $2 \mathrm{mmol}_{\mathrm{c}} \mathrm{dm}^{-3}$, valores de 33,6 e 71,6 $\mathrm{mmol}_{\mathrm{c}} \mathrm{dm}^{-3} \mathrm{de} \mathrm{SB}$ e CTC, respectivamente, e saturação por bases de $47 \%$.

$\mathrm{O}$ delineamento experimental foi o de blocos casualizados, com quatro repetições. O experimento foi constituído de nove tratamentos (consórcios) da cultura do milho com: Panicum maximum cv. Tanzânia semeado simultaneamente (MTS) ou por ocasião da adubação nitrogenada de cobertura (MTC); Panicum maximum cv. Mombaça semeado simultaneamente (MMS) ou por ocasião da adubação nitrogenada de cobertura (MMC); Brachiaria brizantha cv. MG-5 semeado simultaneamente (MBS) ou por ocasião da adubação nitrogenada de cobertura (MBC); Brachiaria ruziziensis semeado simultaneamente (MRS) ou por ocasião da adubação nitrogenada de cobertura (MRC); e milho cultivado solteiro (MCS). As dimensões das parcelas foram de $25 \mathrm{~m}$ de comprimento com quatro linhas espaçadas de $0,90 \mathrm{~m}$ para a cultura do milho.

O híbrido simples utilizado foi o DKB 390 YG de ciclo precoce, semeado em 16/12/2009, com adubação de semeadura realizada com $400 \mathrm{~kg} \mathrm{ha}^{-1}$ da fórmula 04-30-10, igualmente para todos os tratamentos, baseada na análise do solo e na tabela de recomendação de adubação para a cultura do milho irrigado, para o Estado de São Paulo, conforme descrito por Cantarella et al. (1997).

As sementes forrageiras foram semeadas na entrelinha do milho, em espaçamento de $0,34 \mathrm{~m}$, na quantidade

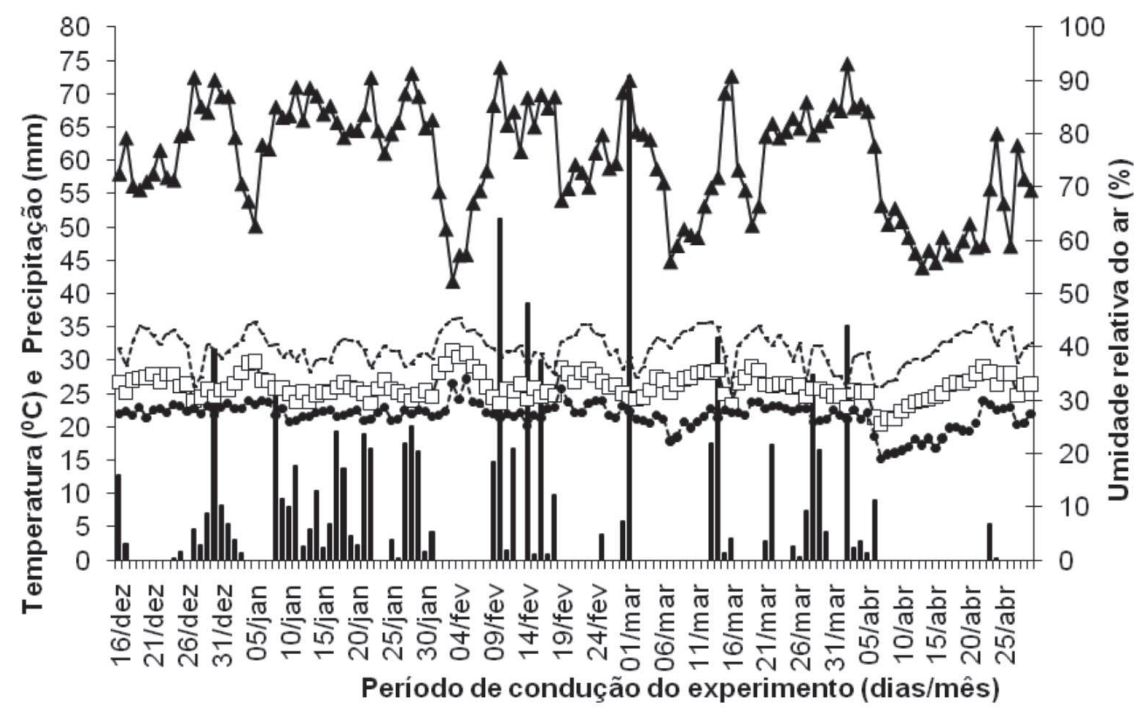

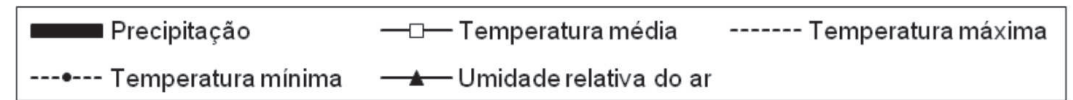

Figura 1. Precipitação pluvial $(\mathrm{mm})$, umidade relativa do $\operatorname{ar}(\%)$ e temperaturas $\left({ }^{\circ} \mathrm{C}\right)$ máxima, média e mínima durante a condução do primeiro experimento. 
de $7 \mathrm{~kg}$ de sementes puras viáveis ha ${ }^{-1}(\mathrm{VC}=76 \%)$, realizando-se nas modalidades em que as forrageiras foram semeadas simultaneamente ao milho operação mecanizada com outra semeadora-adubadora de discos para SPD, enquanto nas modalidades em que as forrageiras foram semeadas por ocasião da adubação nitrogenada de cobertura as sementes foram misturadas ao adubo, minutos antes da semeadura, e acondicionadas no compartimento de fertilizante da semeadora-adubadora. As sementes das forrageiras foram depositadas, mecanicamente, no solo à profundidade de $0,03 \mathrm{~m}$.

A emergência do milho ocorreu em 23/12/2009, enquanto as forrageiras do gênero Brachiaria tiveram sua emergência em 28/12/2009 e 05/02/2010 e a do gênero Panicum em 31/12/2009 e 08/02/2010 para as modalidades de cultivo simultâneo e por ocasião da adubação nitrogenada de cobertura do milho, respectivamente. Aos 20 dias após a emergência do milho (DAE), efetuou-se a aplicação da subdose do herbicida Sanson, na dose de $200 \mathrm{~mL}$ do i.a. $\mathrm{ha}^{-1}$, visando a amenizar o crescimento das forrageiras e, consequentemente, evitar a competição dessas com o milho. Essas operações foram efetuadas com auxílio de um pulverizador tratorizado de barras, com $12 \mathrm{~m}$ de comprimento, utilizando-se bicos tipo leque, espaçados em 0,50 m. Quando a cultura do milho atingiu o estádio V6 (seis folhas totalmente desdobradas), em 29/01/2010, realizou-se a adubação de cobertura em todos os tratamentos, aplicando $100 \mathrm{~kg} \mathrm{ha}^{-1}$ de nitrogênio na forma de ureia. A colheita manual do milho foi realizada em 29/04/2010, correspondendo a 127 DAE.

A produtividade de grãos (PG) foi determinada pela coleta das plantas contidas nas duas linhas centrais de cada parcela. Após a trilhagem mecânica, os grãos foram quantificados, e os dados transformados em $\mathrm{kg} \mathrm{ha}^{-1}$, a $13 \%$ (base úmida).

Visando verificar a diferença estatística da produtividade de grãos de milho entre os tratamentos, realizou-se análise de variância pelo teste $\mathrm{F}(\mathrm{p}<0,05)$ e, posteriormente, a comparação de médias pelo teste Tukey ( $\mathrm{p}<$ $0,05)$, utilizando-se o programa estatístico Sisvar® (Ferreira, 2008).

\section{Avaliação do desempenho econômico}

Os custos variáveis por modalidade de cultivo foram estimados a partir dos coeficientes técnicos dos insumos e operações registrados no experimento, extrapolados para um hectare. Com os valores dos insumos e operações com preços vigentes em novembro de 2009 (Agrianual, 2010; IEA, 2009), acrescentando ao COE outras despesas como 5\% do COE, taxa média estimada por Martin et al. (1998), obteve-se o Custo Operacional Total (COT) para cada tratamento estudado (Matsunaga et al., 1976). As produtividades de grãos obtidas em cada sistema auxilia- ram na obtenção da receita bruta, sendo a produtividade em kg ha-1 transformada em sacas de $60 \mathrm{~kg} \mathrm{ha}^{-1}$, utilizando-se o preço médio recebido pelo produtor referente aos últimos 5 anos (2005 a 2010) em São Paulo, SP (IEA, 2009). Conforme metodologia contida em Martin et al. (1998), calculou-se, em planilhas eletrônicas, o Lucro Operacional (LO) como a diferença entre a RB - COT.

\section{RESULTADOS E DISCUSSÃO}

Na Tabela 1 verifica-se para os consórcios do milho com forrageiras dos gêneros Panicum e Brachiaria que o maior gasto com insumos foi com a compra das sementes de milho transgênico $(45,88 \%$, em média), seguido das despesas com adubo de plantio (NPK) e de cobertura (ureia) (38,52\%, em média). Isso ocorreu em razão da exigência do consórcio da cultura do milho com as forrageiras, demandando grandes quantidades de fertilizantes para altas produtividades de grãos e utilização do residual desses fertilizantes pela forragem para a formação posterior da pastagem. Aguiar et al. (2008), analisando economicamente práticas culturais antecedendo o milho, verificaram que em relação ao manejo do solo o SPD/pousio foi o que se destacou, apresentando maior relação benefício/custo sem adição de nitrogênio mineral, visto que o gasto com fertilizantes é muito alto, e no pousio encontram-se diversas plantas responsáveis pela melhoria dos atributos físicos do solo. Porém, um dos problemas da utilização do pousio como manejo do solo é o aumento do banco de sementes de plantas daninhas na área. Assim, a consorciação com espécies forrageiras pode ser a solução para se ter o benefício da diversificação, obtido em muitos casos com a utilização do pousio.

Quanto às despesas com operações, o maior gasto foi com a irrigação por pivô central $(45,88 \%)$, seguido com a da colheita mecanizada $(18,05 \%)$ (Tabela 1). Contudo, ressalta-se que a irrigação do milho consorciado com forrageiras pode ser desnecessária, dependendo do ano agrícola e da região de cultivo. Segundo Macedo (2009), os sistemas de ILP possibilitam a utilização mais eficiente de equipamentos e o aumento de emprego e renda no campo.

Na Tabela 2, constam a produtividade de grãos (saca $60 \mathrm{~kg} \mathrm{ha}^{-1}$ ), Receita Bruta (R \$/ha), o custo com Operações Totais ( $\mathrm{R} \$ \mathrm{ha})$, Lucro Operacional ( $\mathrm{R} / \mathrm{ha}$ ) e o Índice de Lucratividade (\%), sendo este o indicador que estabelece um índice percentual para representar o lucro obtido na atividade; ou seja, é a porcentagem da receita que representa o lucro da cultura do milho consorciada em diferentes modalidades com as forrageiras dos gêneros Panicum e Brachiaria no ano agrícola 2009/2010.

Com relação à produtividade de grãos, não houve diferença significativa entre o milho cultivado solteiro (MCS) e as modalidades de milho consorciado com forrageiras 
(Tabela 2). Tal resultado provavelmente se deve ao fato de a competição por fatores de produção (água, luz e nutrientes) ter sido baixa. Ressalta-se ainda que o experimento foi irrigado e conduzido em um área com oito anos sobre o sistema de plantio direto.
Esses resultados corroboram com os de Kluthcouski et al. (2000), Kluthicouski e Aidar (2003), Alvarenga et al. (2006) e Borghi e Crusciol (2007), nos quais na maioria dos casos analisados o cultivo consorciado não reduziu, significativamente, a produtividade de grãos de milho,

Tabela 1. Custos operacionais (insumos e operações) para obtenção do desempenho econômico da cultura do milho, em modalidades de cultivo com forrageiras dos gêneros Panicum e Brachiaria (Selvíria-MS, ano agrícola 2009/2010)

\begin{tabular}{|c|c|c|c|c|c|c|}
\hline \multirow{2}{*}{$\frac{\text { Itens }}{\text { Insumos }}$} & \multirow[t]{2}{*}{ Unidade } & \multirow[t]{2}{*}{ Quant. } & \multirow{2}{*}{$\begin{array}{c}\text { Valor unitário } \\
\mathbf{R} \$\end{array}$} & \multirow{2}{*}{$\frac{\text { Valor total }}{\mathbf{R} \$}$} & \multicolumn{2}{|c|}{ Percentual } \\
\hline & & & & & Panicum & Brachiaria \\
\hline Adubo N-P-K (04-30-10) & tonelada & 0,15 & 979,80 & 146,97 & $21,13 \%$ & $21,68 \%$ \\
\hline Adubo Uréia (cobertura) & tonelada & 0,10 & 1175,00 & 117,50 & $16,89 \%$ & $17,33 \%$ \\
\hline Herbicida Sanson & $5\left(\mathrm{~L} \mathrm{ha}^{-1}\right)$ & 0,20 & 261,19 & 10,44 & $1,50 \%$ & $1,54 \%$ \\
\hline Semente de milho DKB 390 YG & $20\left(\mathrm{~kg} \mathrm{ha}^{-1}\right)$ & 1,0 & 315,00 & 315,00 & $45,29 \%$ & $46,46 \%$ \\
\hline Semente de capim-tanzânia & $\begin{array}{c}\mathrm{kg} \mathrm{ha}^{-1} \\
(\mathrm{VC}=76 \%)\end{array}$ & 10,0 & 10,56 & 105,60 & $15,18 \%$ & - \\
\hline Semente de capim-mombaça & $\begin{array}{c}\mathrm{kg} \mathrm{ha}^{-1} \\
(\mathrm{VC}=76 \%)\end{array}$ & 10,0 & 10,56 & 105,60 & $15,18 \%$ & - \\
\hline Semente de capim-brizantha & $\begin{array}{c}\mathrm{kg} \mathrm{ha}^{-1} \\
(\mathrm{VC}=76 \%)\end{array}$ & 10,0 & 8,80 & 88,00 & - & $12,98 \%$ \\
\hline Semente de capim-ruziziensis & $\begin{array}{c}\mathrm{kg} \mathrm{ha}^{-1} \\
(\mathrm{VC}=76 \%)\end{array}$ & 10,0 & 8,80 & 88,00 & - & $12,98 \%$ \\
\hline Total de insumos (Panicum) & & & & 695,51 & & \\
\hline Total de insumos (Brachiaria) & & & & 677,91 & & \\
\hline \multicolumn{7}{|l|}{ Operações } \\
\hline Dessecação inicial & $\mathrm{HM}$ & 0,4 & 55,00 & 22,00 & \multicolumn{2}{|c|}{$3,38 \%$} \\
\hline Semeadura milho & $\mathrm{HM}$ & 0,8 & 130,00 & 104,00 & \multicolumn{2}{|c|}{$15,97 \%$} \\
\hline Adubação de cobertura & $\mathrm{HM}$ & 0,8 & 56,00 & 44,80 & \multicolumn{2}{|c|}{$6,88 \%$} \\
\hline Colheita de grãos & $\mathrm{HM}$ & 1,0 & 117,50 & 117,50 & \multicolumn{2}{|c|}{$18,05 \%$} \\
\hline Semeadura simultânea do capim & $\mathrm{HM}$ & 1,0 & 68,00 & 68,00 & \multicolumn{2}{|c|}{$10,44 \%$} \\
\hline Irrigação pivô central & $\mathrm{mm}$ & 108,0 & 2,73 & 294,84 & \multicolumn{2}{|c|}{$45,28 \%$} \\
\hline Total de operações & - & & 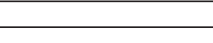 & 651,14 & \multicolumn{2}{|c|}{$100 \%$} \\
\hline
\end{tabular}

* Os custos dos itens um a oito (Insumos) e um a seis (Operações) foram considerados em todas as modalidades de cultivo, com as respectivas sementes forrageiras de cada consórcio. Nas modalidades na qual a forrageira foi semeada simultaneamente ao milho, incluiuse o item 5 (Operações). Investimentos iniciais com preparo de solo e calagem não foram realizados, por se tratar de SPD com oito anos.

Tabela 2. Produtividade de grãos (saca $60 \mathrm{~kg} / \mathrm{ha}$ ), receita bruta (R $\$ / \mathrm{ha})$, custo com operações totais (R $\$ / \mathrm{ha})$, lucro operacional (R\$/ ha) e índice de lucratividade (\%) da cultura do milho consorciado em diferentes modalidades com forrageiras dos gêneros Panicume Brachiaria e do milho em cultivo solteiro (Selvíria-MS, ano agrícola 2009/2010)

\begin{tabular}{|c|c|c|c|c|c|}
\hline Trat. Milho & $\begin{array}{c}\text { Sacas } \\
(60 \mathrm{~kg} / \mathrm{ha})\end{array}$ & $\begin{array}{c}\text { Receita Bruta } \\
\text { (R\$/ha) }\end{array}$ & $\begin{array}{c}\text { COT } \\
(\mathbf{R} \$ / \mathbf{h a})\end{array}$ & $\begin{array}{c}\text { LO } \\
\text { (R\$/ha) }\end{array}$ & $\begin{array}{c}\text { IL } \\
(\%)\end{array}$ \\
\hline $1-$ MTS & $137 a^{*}$ & $2.435,86 * *$ & $1.336,21$ & $1.099,65$ & 45,144 \\
\hline $2-\mathrm{MTC}$ & $115 \mathrm{a}$ & $2.044,70$ & $1.278,65$ & 766,05 & 37,465 \\
\hline 3 - MMS & $133 \mathrm{a}$ & $2.364,74$ & $1.336,21$ & $1.028,53$ & 43,494 \\
\hline $4-\mathrm{MMC}$ & $105 \mathrm{a}$ & $1.866,90$ & $1.278,65$ & 588,25 & 31,509 \\
\hline $5-\mathrm{MBS}$ & $130 \mathrm{a}$ & $2.311,40$ & $1.318,60$ & 992,80 & 42,952 \\
\hline $6-\mathrm{MBC}$ & $126 \mathrm{a}$ & $2.240,28$ & $1.261,05$ & 979,23 & 43,710 \\
\hline $7-\mathrm{MRS}$ & $137 \mathrm{a}$ & $2.435,86$ & $1.318,61$ & $1.117,25$ & 45,866 \\
\hline $8-\mathrm{MRC}$ & $118 \mathrm{a}$ & $2.098,04$ & $1.261,05$ & 836,99 & 39,890 \\
\hline $9-\mathrm{MCS}$ & $112 \mathrm{a}$ & $1.991,36$ & $1.162,61$ & 828,75 & 41,617 \\
\hline DMS $(5 \%)$ & 39 & & & & \\
\hline C.V. $(\%)$ & 13,06 & & & & \\
\hline
\end{tabular}

*Médias seguidas das mesmas letras nas colunas não diferem significativamente pelo teste de Tukey a 5\%. ${ }^{* *}$ Preço médio de venda da saca de $60 \mathrm{~kg}$ de grãos de milho (últimos cinco anos) - Estado de São Paulo: R\$ 17,78. 
como verificado no presente trabalho. De acordo com Kluthicouski e Aidar (2003), isso ocorre, possivelmente, em virtude da ausência de aplicação das doses normais de herbicida graminicida, em pós-emergência, reduzindo possíveis efeitos fitotóxicos na cultura do milho.

No norte das grandes planícies dos Estados Unidos, a diversificação de sistemas de cultivo com forrageiras também aumentou a produtividade das culturas de grãos, reduziu a pressão das plantas daninhas e melhorou a qualidade física do solo (Entz et al., 2002).

Em trabalho semelhante realizado por Pariz et al. (2009), os capins Tanzânia e Ruziziensis, em ambas as modalidades de consórcio, também não comprometeram a produtividade do milho. Conforme Kluthcouski et al. (2000), quando o milho atinge a maturidade fisiológica retorna a luminosidade nas entrelinhas da cultura, permitindo o pleno estabelecimento da forrageira, de tal forma que em 50 a 70 dias após a colheita a pastagem estará em condições de ser utilizada como forragem no período de outonoinverno, ou mesmo na impossibilidade de se realizar pecuária ser dessecada, visando à formação de palha para a continuidade do SPD.

As produtividades mais elevadas de grãos foram observadas nos consórcios do MTS (Milho $+P$. maximum cv. Tanzânia semeados simultaneamente) e MRS (Milho + B. ruziziensis semeados simultaneamente) (137 sacas de $60 \mathrm{~kg}$ por hectare), entretanto esses não diferiram significativamente dos demais tratamentos (Tabela 2). Apesar de ambos os tratamentos terem apresentado RB iguais ( R \$ 2.435,86/ha), o COT do MTS foi mais elevado (R\$ $1.336,21 / \mathrm{ha})$, em razão das suas sementes terem o valor mais elevado que o das demais (com exceção do Mombaça, que teve o mesmo valor), consequentemente o LO e o IL do MRS foram mais elevados ( $\mathrm{R} \$ 1.117,25 /$ ha e $45,19 \%$, respectivamente) em comparação aos do MTS, de R\$ $1.099,65 /$ ha e $45,14 \%$, respectivamente.

Pântano (2003), ao analisar os custos de implantação de um sistema de ILP com milho consorciado com Brachiaria brizantha, no município de Ilha Solteira - SP, obteve um custo total de $\mathrm{R} \$ 1.115,35$ por hectare, valor esse menor do que o encontrado no presente estudo. Neste sistema, a produtividade média de milho entre os consórcios foi de 7.564,19 $\mathrm{kg} \mathrm{ha}^{-1}$ (126 sacas ha-1), o que daria uma receita bruta de $\mathrm{R} \$ 2.269,26$, considerando-se um valor de mercado de $\mathrm{R} \$ 18,00$ a saca de $60 \mathrm{~kg}$; sendo, portanto, a produtividade de grãos, a RB e o preço da saca de milho muito parecidos aos obtidos no presente estudo. Descontando-se o custo de produção, esse autor obteve uma receita líquida de $\mathrm{R} \$ 1.153,91$ por hectare, o que representa uma lucratividade de $50,85 \%$, valor esse um pouco maior do que os IL obtidos no presente estudo. Tal diferença pode ser explicada pelo menor COT registrado no experimento de Pântano (2003).
O tratamento com produtividade mais baixa de grãos foi o MMC (Milho + P. maximum cv. Mombaça semeado por ocasião da adubação nitrogenada de cobertura), (105 sacas de $60 \mathrm{~kg} \mathrm{ha}^{-1}$ ), porém não houve diferença significativa entre os demais (Tabela 2). Resultados semelhantes foram obtidos por Pariz et al. (2009), em que o tratamento MMS (Milho + capim-mombaça, semeados simultaneamente) foi o que proporcionou menor produtividade de grãos, em razão da competição ocasionada pela forrageira.

Apesar do COT do MMC não ter sido o mais alto (R\$ $1.278,65 / \mathrm{ha}$ ), esse apresentou o menor LO e IL dentre as nove modalidades de tratamento, $\mathrm{R} \$ 588,25 /$ ha e $31,51 \%$, respectivamente. $\mathrm{O}$ segundo e o terceiro tratamentos com produtividades mais baixas foram o MCS (cultivo solteiro do milho) e o MRC (Milho + B. ruziziensis semeada por ocasião da adubação nitrogenada de cobertura), com 105 sacas de $60 \mathrm{~kg} \mathrm{ha}^{-1}$ e 112 de $60 \mathrm{~kg} \mathrm{ha}^{-1}$, respectivamente (Tabela 2).

Quanto aos indicadores econômicos, o MCS apresentou a segunda menor RB, o menor COT, o terceiro menor LO e o sexto melhor IL dentre as nove modalidades de tratamento (Tabela 2).

Pode-se constatar com esses resultados que quando o milho é cultivado em consórcio com forrageiras simultaneamente, mesmo com maiores investimentos, a produtividade de grãos do milho resultou em ganhos maiores que o próprio investimento; portanto, essa atividade é muito interessante financeiramente, principalmente para os pequenos agricultores que buscam diversificar suas atividades e alcançar lucratividade. Além disso, a produção das forrageiras possibilita gerar renda com a produção de carne e leite.

Para os produtores salienta-se que, além de optar pelos tratamentos com maior índice de lucratividade no ILP, é importante também escolher corretamente a forrageira conforme a fertilidade do solo. Segundo Werner et al. (1997), as forrageiras do gênero Panicum são mais exigentes em fertilidade do solo que as do gênero Brachiaria.

\section{CONCLUSÕES}

Os sistemas de consórcio de forrageiras com milho não reduziram a produtividade de grãos em relação ao milho cultivado sem consórcio.

O consórcio mais recomendado foi milho cultivado com B. ruziziensis, principalmente em semeadura simultânea, pois além da produtividade elevada, o preço dessa semente é o mais acessível, alcançando maior IL que os demais tratamentos.

Em geral, os cultivos simultâneos apresentaram maior RB, maior COT (devido à aplicação do herbicida Sanson), menor LO (com exceção do MBS) e maior IL. 


\section{REFERÊNCIAS}

Aguiar RA, Silveira PM, Moreira JAA, Wander AE (2008) Análise econômica de diferentes ráticas culturais na cultura do milho (Zea mays L.). Pesquisa Agropecuária Tropical, 38:241-248.

Agrianual (2010) Anuário da Agricultura Brasileira. São Paulo: Instituto FNP, 502 p.

Allen VG, Baker MT, Segarra E \& Brown CP (2007) Integrated irrigated crop-livestock systems in dry climates. Agronomy Journal, 99:346-360.

Alvarenga RC, Cobucci T, Kluthcouski J, Wruck FJ, Cruz JC \& Gontijo Neto MM (2006) Cultura do milho na integração lavoura-pecuária. Informe Agropecuário, 27:106-126.

Ambrosi I, Santos HP, Fontaneli RS \& Zoldan SM (2001) Lucratividade e risco de sistemas de produção de grãos combinados com pastagens de inverno. Pesquisa Agropecuária Brasileira, 36:1213-1219

Borghi, E \& Crusciol CAC (2007) Produtividade de milho, espaçamento e modalidade de consorciação com Brachiaria brizantha no SPD. Pesquisa Agropecuária Brasileira, 42:163-171.

Cantarella H, Raij, B. van. \& Camargo CEO. Cereais. In: Raij, B. van; Cantarella H, Quaggio JA \& Furlani AMC (1997) eds. Recomendações de adubação e calagem para o Estado de São Paulo. 2.ed. Campinas, Instituto Agronômico de Campinas/Fundação IAC. p.45-71.

Cobucci T, Wruck J, Kluthcouski J, Cavalcante LM, Martha Júnior GB, Carnevalli RA, Teixeira SR, Polinária A, Teixeira M (2007) Opções de integração lavoura-pecuária e alguns de seus aspectos econômicos. Informe Agropecuário, 28:64-79.

Costa FP \& Macedo MCM (2001) Economic evaluation of agropastoral systems: some alternatives for Central Brazil. In: Workshop on Agropastoral System in South America. Japan, Anais: JIRCAS. p.57-62.

Companhia Nacional de Abastecimento (CONAB) - CONAB (2010) Safra brasileira: grãos, $5^{\circ}$ levantamento. Disponível em: <http:// www.conab.gov.br>. Acessado em: 15 de fevereiro de 2011.

Entz MH, Baron VS, Carr PM, Meyer DW, Smith Júnior SR, McCaughey WP (2002) Potential of forages to diversify cropping systems in the Northern Great Plains. Agronomy Journal, 94:240-250.

Ferreira DF (2008) SISVAR: um programa para análises e ensino de estatística. Revista Symposium, 6:36-41.

Fontaneli RS, Ambrosi I, Santos HP, Ignaczak JC \& Zoldan SM (2000) Análise econômica de sistemas de produção de grãos com pastagens anuais de inverno, em sistema de plantio direto. Pesquisa Agropecuária Brasileira, 35:2129-2137.

Instituto de Economia Agrícola - IEA (2009) Preços médios mensais recebidos pelos agricultores e área da produção de milho em 2009/2010. Disponível em: < http://www.iea.sp.gov.br/out/ index.php >. Acessado em 19 de janeiro de 2011.

Jakelaitis A, Silva AA, Silva AF, Silva LP, Ferreira LR, Vivian R (2006) Efeitos de herbicidas no controle de plantas daninhas, crescimento e produção de milho e Brachiaria brizantha em consórcio. Pesquisa Agropecuária Tropical, 36:53-60.

Jakelaitis A, Silva AF, Silva AA, Ferreira LR, Freitas FCL \& Viana RG (2005) Influência de herbicidas e de sistemas de semeadura de Brachiaria brizantha consorciada com milho. Planta daninha, 23:59-67.

Kluthcouski J, Cobucci T, Aidar H, Yokoyama LP, Oliveira IP, Costa JLS, Silva JG, Vilela L, Bacellos AO \& Magnabosco CU (2000) Sistema Santa Fé - Tecnologia Embrapa: integração lavoura-pecuária pelo consórcio de culturas anuais com forrageiras, em áreas de lavoura, nos sistemas direto e convencional. Santo Antônio de Goiás, Embrapa Arroz e Feijão, p.28 (Circular Técnica, 38).
Kluthcouski J \& Aidar H (2003) Uso da integração lavoura-pecuária na recuperação de pastagens degradadas. In: Kluthcouski, J, Stone LF \& Aidar H (Ed.). Integração lavoura-pecuária. 1.ed. Santo Antonio de Goiás, Embrapa Arroz e Feijão, p.185-223.

Landers JN (2007) Tropical crop-livestock systems in conservation agriculture: the Brazilian experience. In: Integrated Crop Management. v.5, 1.ed. Rome, Food and Agriculture Organization of the United Nations (FAO), p.92.

Macedo MCM (2009) Integração lavoura e pecuária: o estado da arte e inovações tecnológicas. Revista Brasileira de Zootecnia, 38:133-146.

Martha JR GB, Vilela L \& Sousa DMG (2008) Economia de fertilizantes na integração lavoura-pecuária no Cerrado. Revista de Política Agrícola, 17:14-19.

Martin NB, Serra R, Oliveira MDM, Angelo JA, Okawa H (1998) Sistema integrado de custos agropecuários - CUSTAGRI. Informações Econômicas, 28:7-28.

Muniz LC, Figueiredo RS, Magnabosco CU, Wander AE \& Martha Júnior GB (2007) Análise de risco da integração lavoura e pecuária com a utilização do system dynamics. In: Congresso da Sociedade Brasileira de Economia, Administração e Sociologia Rural, 45, Londrina. Anais, SBEASR, CD-ROM.

Matsunaga M, Bemelmans PF \& Toledo P (1976) Metodologia de custo de produção utilizada pelo IEA. Agricultura em São Paulo, 23:123-139

Muniz LC (2007) Avaliação bio-econômica em sistema de integração lavoura-pecuária. Dissertação de Mestrado. Escola de Agronomia e Engenharia de Alimentos, Universidade Federal de Goiás, Goiânia. 91p.

Pântano, AC (2003) Semeadura de Brachiaria em consorciação com milho em diferentes espaçamentos na integração agricultura-pecuária no plantio direto. Dissertação de Mestrado. Universidade Estadual Paulista, Ilha Solteira. 60p.

Pariz CM, Andreotti M, Tarsiano MAA, Bergamaschine AF, Buzetti S \& Chioderoli CA (2009) Desempenhos técnicos e econômicos da consorciação de milho com forrageiras dos gêneros Panicum e Brachiaria em sistema de integração lavoura-pecuária. Pesquisa Agropecuária Tropical, 39:360-370.

Portela CM de O (2003) Efeito de herbicidas e diferentes populações de forrageiras consorciadas com as culturas de soja e milho, no Sistema Santa Fé. Dissertação de Mestrado. Universidade Federal de Goiás, Goiânia. 68p.

Tracy BF \& Zhang Y (2008) Soil compaction, corn yield response, and soil nutrient pool dynamics within an integrated croplivestock system in Illinois. Crop Science, 48:1211-1218,

Trecenti R, Oliveira MC \& Hass G (2008) Integração lavoura-pecuária-silvicultura. Brasília, MAPA/SDC, p.54 (Boletim técnico).

Tsunechiro, A; Oliveira, MDM.; Furlaneto, FPD. \& Duarte, AP (2006) Análise técnica e econômica de sistemas de produção de milho safrinha, região do Médio Paranapanema, estado de São Paulo. 2006. Artigo em Hypertexto. Disponível em: <http:// www.infobibos.com/Artigos/2006_3/Safrinha/index.htm>. Acessado em: 05 de janeiro de 2012.

Werner, JC; Paulino, VT; Cantarella, H; Andrade, NO \& Quaggio, JA (1997) Forrageiras. In: Raij, B van; Cantarella, H; Quaggio, JA \& Furlani, AMC (Eds.) Recomendações de Adubação e Calagem para o Estado de São Paulo. 2ed. Campinas, Instituto Agronômico de Campinas/Fundação IAC. p.263-273. 